Book Review 


\section{The Known Unknowns of Translation Studies*}

\section{*Brems, E., Meylaerts, R., \& Van Doorslaer, L. (Eds.). (2014). The Known Unknowns of Translation Studies. Amsterdam: John Benjamins Publishing Company.}

Deepa $V$.

The Known Unknowns of Translation Studies, edited by Elke Brems, Reine Meylaerts and Luc van Doorslaer is a collection of essays by eminent scholars within Translation Studies that attempts to look into the explored and unexplored areas within Translation Studies. It reflects the journey of Translation Studies as an independent interdisciplinary area of research since 1970s, identifies the present state of Translation Studies as a discipline focusing on the changing tendencies and directions within Translation Studies and its sub-domains and charts out its future directions and perspectives.

This book is an extended and modified version of the special issue of the Target 24:1 (Brems, Meylaerts and van Doorslaer, 2012) which in turn was an outcome of the conference 'The Known Unknowns of Translation Studies' organised by the University of Leuven in Belgium in August 2009. This book is published under Benjamins Current Topics series which publish special issues of established journals to make them reach out to a wider audience. With its simplicity and lucid narrative style, this work undoubtedly meets this goal as it appeals to anyone within or outside Translation Studies.

The first article by Susan Bassnett sets in the context for further discussions by tracing the successful story of Translation Studies as a discipline since the conference at University of Leuven in 1975. 
She delivers an account of the nature and concerns of Translation Studies as an emerging discipline, its growth, development and its achievements. It is beyond any doubts that Translation Studies as a discipline has been successful in achieving its goals and targets, in questioning the orthodoxy and establishments. However, the present situation of Translation Studies pauses certain concerns and challenges to Translation Studies scholars. One of the concerns raised by Bassnett is the place Translation Studies has in the academia and the impact the discipline of Translation Studies has on other disciplines. Though the term translation is being used immensely in the academia, most of its usages are coming from outside the discipline and translation is used in a metaphorical sense to refer to the multilingual multicultural situations with no proper dues given to the 'actual realities of interlingual transfer process (23).' Such situation, according to her, demands introspection. Translation Studies needs to redefine itself, to broaden its reach and scope, to widen its goals and targets and to negotiate with the changing linguistic, cultural and temporal boundaries in new ways. It has to build effective communicative channels with other related disciplines and engage in more interdisciplinary, collaborative projects.

In a globalised world, where multilingualism and multiculturalism are realities, the actual processes of translation and interpreting become part of everyday life. Though translating and interpreting has been a major concern of Translation Studies from the beginning, many of the authors feel that Translation Studies could not reach out to these areas in an effective way. Functional Translatology is one such area. Christiane Nord traces the emergence of functionalist approach in Germany back to the 1970s. The Skopos theory proposed by Vermeer has been used to develop 
Deepa V.

translation methodology, translation oriented text analysis, quality assessment and so on in the 1980s. However, it was not recognised within the academic circle until recently. Even now the approach is different. According to Nord, while its usefulness and applicability in translating advertisements and operating instructions are widely acknowledged, the same approach for biblical translation and literary translation is not accepted. However, there is significant improvement in the present context. With the growing demand for translation and interpreting in mulilingual and multicultural countries like South Africa, there is a growing interest in the Functionalist approach. There is a need for more research in these fields. Translational action like cross-cultural consulting, intercultural technical writing etc. offers new scope for research. Miriam Shlesinger and Noam Ordan's study attempts to look into the interrelationship between translation and interpreting and also written and oral translations. Their study aims to look at the way the modalities, whether written or spoken, influence translation than ontology, whether original or translated.

Another unexplored area within Translation Studies is the Translation Process Research (TPR). Though James Holmes in his famous article 'The Name and Nature of Translation Studies' allots an entire sub-branch of Descriptive Studies for the research on the process of translation, it is unfortunate that till recently, this area has been largely unexplored within Translation Studies as the focus of most of the researches within Translation Studies has been the production, reception and the product of translation. According to Arnt Lykke Jakobsen, the attempts to understand the writing process through observational protocols can be seen in the early 1970s itself in the US. These attempts were carried forward by the pioneers of 
think-aloud methods in the 1980s. However, it was with the development of keylogging, developed out of combination of key stroke logging and eye tracking supported by computational and statistical data analysis that marked the start of Translation Process Research. Keystroke logging along with gaze data gives a closer view of the way text is read and comprehended through monitoring eye movements while reading the text, checking the text, re-reading etc. Though there are experiments happening in this area, the ecological validity of these laboratory experiments is largely unknown and unexplored.

While Translation Process Research looks at the process involved in translation activity through its external manifestations, Maria Tymozko argues for the need to look at the actual process going on within the human brain at the cognitive or neurological level of both the translator and the receiver through a collaborative research by translation studies scholars and neurophysiologists. She points out that some of the current areas of research in neuroscience especially on perception, memory and plasticity can contribute immensely to Translation Studies. The research in this field may question and challenge some of the existing views and understandings about translation itself. For instance, the finding that perception is not merely a sense data rather it is shaped by culture and experience can have huge impact on Translation Studies especially in translator training as translation is highly influenced by our perception of the source as well as the target culture. Thus an understanding of the possibility of deconstructing such formative experiences and neurological processes that shapes our perception through self- reflexivity can be of huge help in translator training.

In Christina Schaffner's opinion, though the questions of power relations and the politics of language have gained an important place 
Deepa V.

in Translation Studies research, the actual translations happening in the political situations and institutions like joint letters, press conferences etc. have been rarely explored in TS. While some research have been done within Critical Discourse Analysis identifying certain patterns of language use in particular political settings and an entirely new domain of research that explores the relation between language and politics names 'Political Linguistics' has emerged within Linguistics, Translation Studies, so far, has been largely blind to these issues and concerns. According to Schaffner, the significant role played by translation and interpreting in these domains provide immense scope for research for Translation Studies scholars that can enrich our understandings of power relations, language politics and the like. She argues that 'such discursive elements in the international politics like state visits, joint press conference etc. are highly complex events which are also discursive events which include translational elements' (133).

Sherry Simon employs the concept of translation to understand the aspects of city life. Though there are a number of studies on city, the language aspects of city are largely unexplored. According to her, the complex multilingual, multicultural situations of cities involve translation at various levels. She takes the city of Czernowitz in Central Europe which was home to German, Romanian, Ukranian and Yiddish language and culture as a case study. The convergence, exchanges and interchanges between these languages and cultures have been crucial in shaping the city life of Czernowitz. Therefore, for her, the city is also translational. The translational city, argues Simon, offers a new view into city life and in turn it also offers new perspectives on translation. Looking at cities as translation space using language passage, according to Simon, provides a key to understand the political and cultural tensions of that city. 
What makes this work significant is the very fact that it is a self- reflection of Translation Studies itself. It mirrors the evolution of Translation Studies. This work looks at some of the areas that are not sufficiently engaged with within Translation Studies but may decide the future directions of Translation Studies. These studies stress on the need for Translation Studies to redefine itself. To constantly negotiate with its own boundaries, to revisit and to re examine its nature and concerns in order to respond to the changing societal needs and developments in a globalised digital era.

It opens up in front of the readers, enormous opportunities and scope within Translation Studies. Though the immediate beneficiaries would be students, scholars, practitioners of Translation Studies, anyone outside the discipline can also hugely benefit from it. Though the topics discussed and the terminologies used are technical, it does not obstruct non- Translation Studies audience from understanding the basic arguments of the text. 